\title{
Cerebral pressure autoregulation in traumatic brain injury
}

\author{
Leonardo Rangel-Castilla, M.D., ${ }^{1}$ Jaime Gasco, M.D. ${ }^{1}$ Haring J. W. Nauta, M.D., \\ Ph.D., ${ }^{1}$ David O. OKonkwo, M.D., Ph.D., ${ }^{2}$ and Claudia S. Robertson, M.D. ${ }^{3}$
}

\author{
${ }^{1}$ Division of Neurosurgery, University of Texas Medical Branch, Galveston; ${ }^{3}$ Department of Neurosurgery, \\ Baylor College of Medicine, Houston, Texas; and ${ }^{2}$ Department of Neurosurgery, University of Pittsburgh \\ Medical Center, Pittsburgh, Pennsylvania
}

\begin{abstract}
An understanding of normal cerebral autoregulation and its response to pathological derangements is helpful in the diagnosis, monitoring, management, and prognosis of severe traumatic brain injury (TBI). Pressure autoregulation is the most common approach in testing the effects of mean arterial blood pressure on cerebral blood flow. A gold standard for measuring cerebral pressure autoregulation is not available, and the literature shows considerable disparity in methods. This fact is not surprising given that cerebral autoregulation is more a concept than a physically measurable entity. Alterations in cerebral autoregulation can vary from patient to patient and over time and are critical during the first 4-5 days after injury. An assessment of cerebral autoregulation as part of bedside neuromonitoring in the neurointensive care unit can allow the individualized treatment of secondary injury in a patient with severe TBI. The assessment of cerebral autoregulation is best achieved with dynamic autoregulation methods. Hyperventilation, hyperoxia, nitric oxide and its derivates, and erythropoietin are some of the therapies that can be helpful in managing cerebral autoregulation. In this review the authors summarize the most important points related to cerebral pressure autoregulation in TBI as applied in clinical practice, based on the literature as well as their own experience. (DOI: 10.3171/FOC.2008.25.10.E7)
\end{abstract}

\section{KeY WoRds - cerebral autoregulation - cerebral vasculature • intracranial hypertension • pressure autoregulation • traumatic brain injury}

$\mathrm{T}$ HE outcome of severe TBI has improved with advances in intensive care monitoring and treatment, most notably in Lund, Sweden, and Richmond, Virginia, in the second half of the 20th century. An understanding of the physiology, pathophysiology, monitoring, and treatment of cerebral autoregulation is key in the evolution of the critical care management of severe TBI.

Cerebral pressure autoregulation is the specific intrinsic ability to maintain constant $\mathrm{CBF}$ over a range of blood pressures. Metabolic cerebral autoregulation is the ability of the brain to locally adjust CBF to meet cerebral metabolic requirements. ${ }^{27}$ Metabolic cerebral autoregulation is a distinct entity, and for the purpose of this review we focus on pressure autoregulation.

\footnotetext{
Abbreviations used in this paper: $\mathrm{ARI}=$ autoregulation index; $\mathrm{AVDO}_{2}=$ arteriovenous $\mathrm{O}_{2}$ difference; $\mathrm{CBF}=$ cerebral blood flow; $\mathrm{CBV}=$ cerebral blood volume; $\mathrm{CPP}=$ cerebral perfusion pressure; $\mathrm{CSF}=$ cerebrospinal fluid; $\mathrm{CVR}=$ cerebrovascular resistance; $\mathrm{ETCO}_{2}=$ end-title $\mathrm{CO}_{2}$; ICP = intracranial pressure; iNOS = inducible nitric oxide synthase; $\mathrm{MABP}=$ mean arterial blood pressure; $\mathrm{MCA}=$ middle cerebral artery; $\mathrm{Mx}=$ mean index; $\mathrm{NOS}=$ nitric oxide synthase; $\mathrm{PRx}=$ pressure reactivity index; $\mathrm{sROR}=$ static rate of autoregulation; TBI = traumatic brain injury; $\mathrm{TCD}=$ transcranial Doppler.
}

Cerebral pressure autoregulation is generally observed between a MABP of $\sim 50$ and $150 \mathrm{~mm} \mathrm{Hg}$ (Fig. 1). ${ }^{27}$ Normal CBF in humans varies widely depending on tissue demands but averages around $50 \mathrm{ml} / 100 \mathrm{~g}$ brain tissue/min and is characteristically higher in children and adolescents and lower with advancing age. ${ }^{36}$ Irreversible neuron damage occurs in a time-dependent manner when $\mathrm{CBF}$ is below $10-15 \mathrm{ml} / 100 \mathrm{~g} / \mathrm{min}$, whereas reversible neuronal dysfunction has been noted at a $\mathrm{CBF}$ between 15 and $20 \mathrm{ml} / 100 \mathrm{~g} / \mathrm{min}$ (Fig. 2). ${ }^{2}$ Pressure autoregulation mechanisms protect against cerebral ischemia due to hypotension and against excessive flow (malignant hyperemia) during hypertension, when capillary damage, edema, diffuse hemorrhage, and intracranial hypertension might otherwise result. The loss of or an impairment in cerebral pressure autoregulation carries important ramifications for patients with TBI.

\section{Normal Physiology}

Under normal physiological conditions, cerebral autoregulation is a complex process that involves myogenic, neurogenic, and metabolic mechanisms, possibly acting in combination. The myogenic component is the intrinsic ability of the vascular smooth muscle to con- 


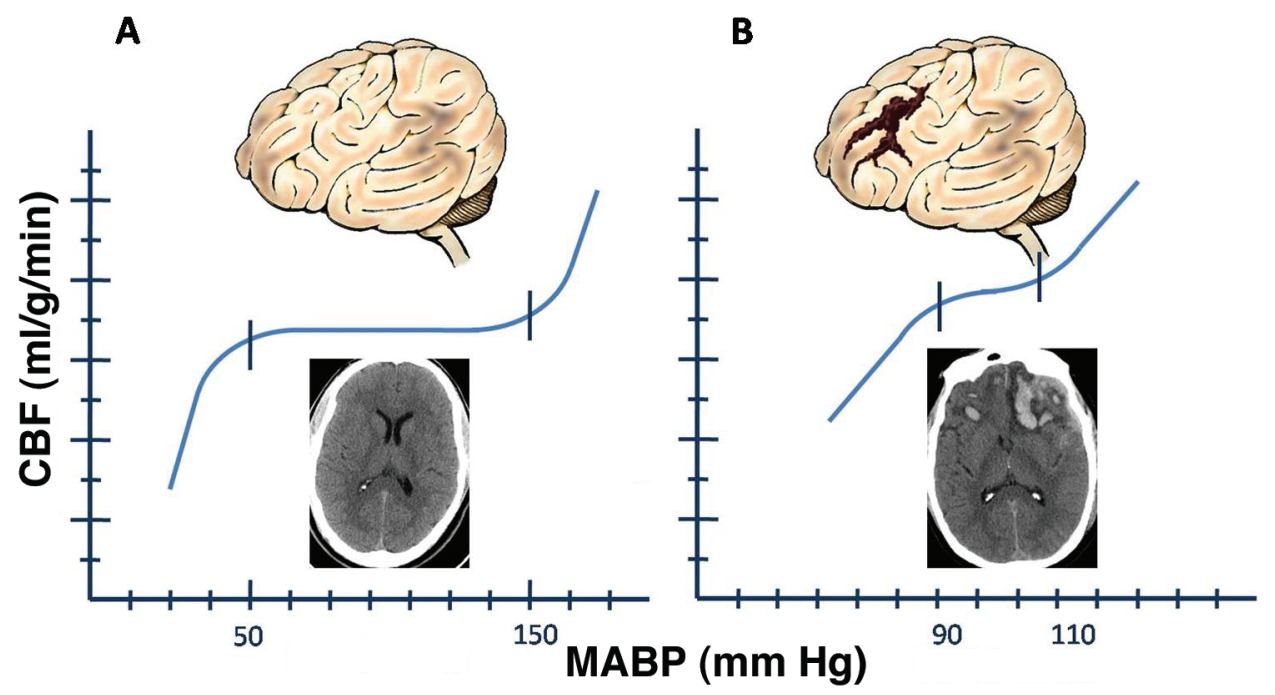

FIG. 1. Graphs showing cerebral pressure autoregulation curves in normal $(A)$ and traumatically injured $(B)$ brain.

strict or dilate in response to changes in transmural pressure. This mechanism can be demonstrated in isolated vessel preparations in which alterations in the intravascular pressures trigger immediate changes in vessel diameter. ${ }^{39}$ The neurogenic mechanism occurs through an extensive nerve supply to midsized vessels. The activation of $\alpha$-adrenergic sympathetic nerves shifts the limits of autoregulation toward higher pressures, and acute denervation (for example, neurogenic shock) shifts the limits of autoregulation toward lower pressures. ${ }^{17}$ During acute hypertensive episodes, the cerebral vasculature responds with vasoconstriction. ${ }^{19}$ The metabolic mechanism probably occurs in smaller vessels that are subject to changes in the local microenvironment that alter vasomotor response. For example, an uncompensated drop in blood pressure results in a decrease in $\mathrm{CBF}$, which in turn leads to an accumulation of $\mathrm{CO}_{2}$ and a depletion of $\mathrm{O}_{2}$. These changes in the microenvironment cause vasodilation to return $\mathrm{CBF}$ back to a normal level. Variations in the $\mathrm{PaCO}_{2}$ exert a profound influence on $\mathrm{CBF}$, with an $\sim 4 \%$ increase in CBF for every 1-mm $\mathrm{Hg}$ increase in $\mathrm{PaCO}_{2}$ and a $4 \%$ decrease in $\mathrm{CBF}$ for every $1-\mathrm{mm} \mathrm{Hg}$ decrease in $\mathrm{PaCO}_{2}$. This arteriolar response has been shown to be mediated by a local effect of $\mathrm{H}^{+}$or in $\mathrm{pH}$ variations in the extracellular fluid surrounding vessels in the brain. ${ }^{41}$ The $\mathrm{PaO}_{2}$ in the normal physiological range does not affect $\mathrm{CBF}$, but when $\mathrm{PaO}_{2}$ falls below $50 \mathrm{~mm} \mathrm{Hg}, \mathrm{CBF}$ increases dramatically.

Autoregulatory vasoconstriction is much smaller (maximum $\sim 8-10 \%$ of baseline diameter) than autoregulatory vasodilation (up to $65 \%$ of baseline diameter). Consequently, much greater changes in CBV occur with hypotension than with hypertension. Autoregulatory vasoconstriction predominantly takes place in the largest arterioles ( $>200 \mu \mathrm{m}$ in diameter), although the bulk of the $\mathrm{CBV}$ is probably contained in smaller vessels, because they are so much more numerous, and in the venous system. ${ }^{4}$ Additionally, endothelium-related factors have been suggested to contribute to autoregulatory responses, and some studies have indicated a possible role for $\mathrm{NO}$ as a vasodilator during reduced $\mathrm{CPP} .{ }^{25}$

\section{Pathophysiology of Cerebral Autoregulation in TBI}

Across multiple studies, $49-87 \%$ of patients with severe TBI have demonstrated an absence of or impairment in autoregulation. ${ }^{4,21}$ Disturbed cerebral autoregulation has been shown to occur in patients after head injury, and in experimental models it has been observed even when

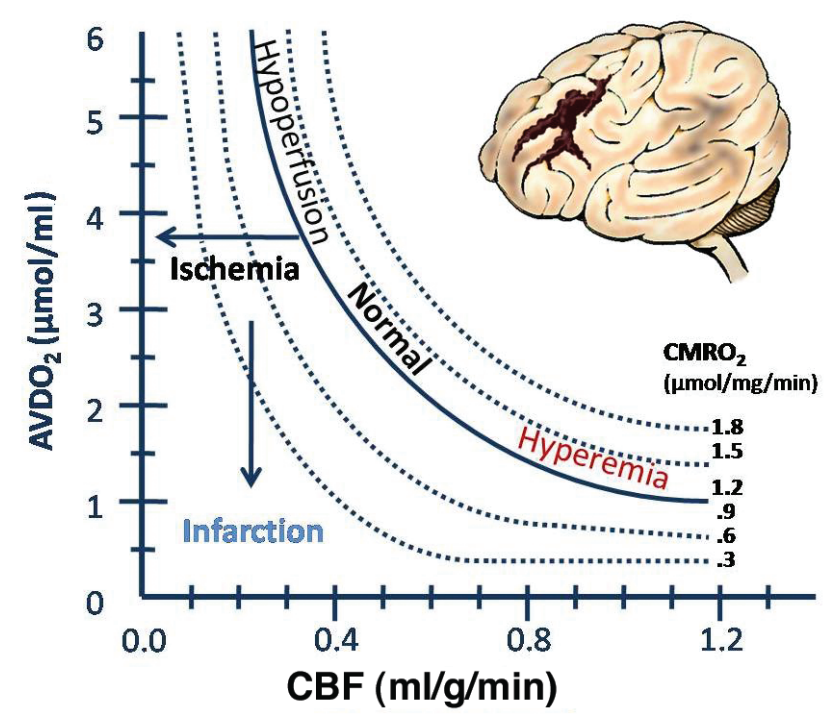

FIG. 2. Graph demonstrating relationships among CBF, cerebral metabolic rate of $\mathrm{O}_{2}\left(\mathrm{CMRO}_{2}\right), \mathrm{AVDO}_{2}$, hyperemia, hypoperfusion ischemia, and infarction in severe TBI. Modified with permission from Robertson CS, Narayan RK, Gokaslan ZL, et al: Cerebral arteriovenous oxygen differences as an estimate of cerebral blood flow in comatose patients. J Neurosurg 70:222-230, 1989. 


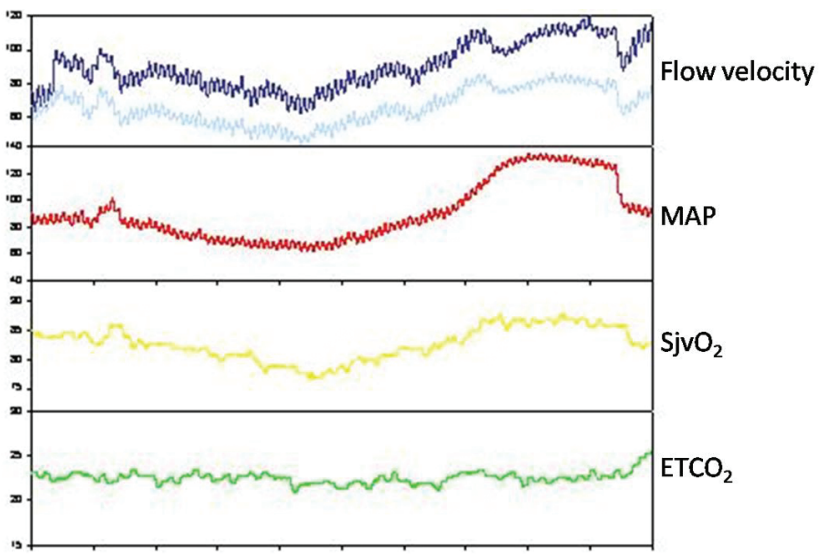

FIG. 3. Graph revealing cerebral hemodynamics (flow velocity and $\mathrm{MABP}$ ) and metabolism (jugular venous $\mathrm{O}_{2}$ saturation and $\mathrm{ETCO}_{2}$ ) and their relationship to sROR test. $\mathrm{SjvO}_{2}=$ jugular venous $\mathrm{O}_{2}$ saturation.

the values of CPP and CBF are normal. ${ }^{14,26,29}$ Cerebral autoregulation can be impaired in any degree of TBI, even mild, and with normal ICP and MABP values. ${ }^{24}$ Patients in whom cerebral autoregulation is impaired or absent have a greater risk of cerebral ischemia if hypotension occurs. When cerebral autoregulation is impaired, sudden increases in MABP can be more easily transmitted into the microcirculation and can contribute to either areas of infarction or secondary hemorrhages and edema. ${ }^{49}$ Moreover, cerebral autoregulation determines the response to a number of drug treatments administered to a patient with severe TBI, including mannitol and pressors.

Impaired cerebral autoregulation may be a significant risk factor for secondary injury in the first few hours after severe TBI, when CBF is reduced in up to $60 \%$ of patients and when patients are most likely to be hemodynamically unstable. ${ }^{5}$ A reduction in CBF after severe TBI is due to the reduced metabolic demands of coma or may represent hypoperfusion or ischemia. Arteriovenous $\mathrm{O}_{2}$ difference measurements demonstrate that even when $\mathrm{CBF}$ is reduced, it often exceeds metabolic requirements. However, in $27 \%$ of patients with severe TBI and CBF as low as $18 \mathrm{ml} / 100 \mathrm{~g} / \mathrm{min}, \mathrm{AVDO}_{2}$ measurements have indicated that $\mathrm{CBF}$ does not meet the metabolic demands of the injured brain. ${ }^{43}$

In the injured brain, cerebral autoregulation predicts $\mathrm{CBV}$, and hence changes in ICP, with changing hemodynamic conditions. When autoregulation is intact, a decrease in CPP results in vasodilation (and increased CBV), leading to increased ICP due to impaired brain compliance. ${ }^{4}$ With defective cerebral autoregulation, any decrease in CPP, regardless of its baseline value, will produce a decrease in CBF. Cerebral blood flow will decrease linearly with $\mathrm{CPP}$ and thus may reach ischemic levels, worsening secondary injury.

Cerebral autoregulation is not an all-or-nothing phenomenon but more typically exists with various degrees of impairment and an irregular distribution throughout the injured brain. It has been shown that autoregulation impairment is worse on the side of the brain in which mass lesions are present. ${ }^{47}$ It is well known that $\mathrm{CBF}$ and cerebral autoregulation are heterogeneous after TBI and tend to be reduced in the immediate vicinity of a contusion. ${ }^{33}$ This finding can be explained by interhemispheric ICP gradients, ${ }^{44}$ local tissue pressure gradients leading to mass shift, and asymmetry of CVR due to a heterogeneous pattern of endothelial dysfunction. There is a surprising but established correlation between the asymmetry of autoregulation and a poor outcome. ${ }^{48}$ Although incompletely understood, a poor outcome is more strongly correlated with asymmetric autoregulation than with globally altered autoregulation. Patients who died after TBI had a worse and mainly asymmetrical autoregulation. ${ }^{44}$

An understanding of the state of cerebral autoregulation permits more individualized critical care of a patient with TBI, as reflected in the most recent guidelines on the management of severe TBI. ${ }^{7-9}$ In patients with impaired autoregulation, attempts to improve CPP values by using vasopressors can precipitate a dangerous CBF (malignant hyperemia). Thus, in the new guidelines, it has been pointed out that patients with intact autoregulation tolerate higher CPP values $(70 \mathrm{~mm} \mathrm{Hg}$ ) than patients with impaired autoregulation, whose target CPP should not be above $60 \mathrm{~mm} \mathrm{Hg}$.

\section{Methods to Assess Cerebral Pressure Autoregulation}

Measuring cerebral pressure autoregulation may provide clinically useful information in treating patients with TBI. Cerebral autoregulation is probably best understood not as a single physical quantity with a simple metric, but rather as a distributed phenomenon, perhaps reflecting large vascular beds. The challenge in establishing appropriate measurement modalities for cerebral autoregulation is made more difficult by other variables that can influence $\mathrm{CBF}\left(\mathrm{PaCO}_{2}\right.$, brain activation, $\mathrm{O}_{2}$ content, hematocrit, and temperature). At present, no single method can be regarded as a gold-standard measure of cerebral autoregulation. So far, there are 2 methods for assessing the status of cerebral autoregulation: static and dynamic. Of the 2, the dynamic measure has greater clinical relevance.

\section{Static Autoregulation}

Most investigators of cerebral autoregulation have looked at the steady-state relationship between CBF and CPP or MABP without considering the time course of changes in flow following changes in pressure (Fig. 3). This approach is the static type used to derive the classic autoregulation curve (Fig. 1). ${ }^{27}$ This curve shows a plateau region that is nearly flat, corresponding to a constant $\mathrm{CBF}$ for changes in MABP over a physiological range (50-170 $\mathrm{mm} \mathrm{Hg}$ ). The most frequently used methods for estimating changes in cerebral perfusion are TCD ultrasonography, xenon-133 clearance, and stable xenon CT-demonstrated CBF. Transcranial Doppler ultrasonography insonation of the MCA is probably the most convenient technique to use in the neurointensive care unit ${ }^{40}$ given that the MCA is most likely to be "visible" to the ultrasound through the thin part of the temporal bone. Other techniques reported 


\section{Rangel-Castilla et al.}

to reflect tissue perfusion include the $\mathrm{AVDO}_{2}$ to estimate CBF changes, electromagnetic flow meters, near-infrared spectroscopy, laser Doppler flowmetry, and jugular venous occlusion plethysmography.

Using TCD ultrasonography to assess cerebral pressure autoregulation, the SROR is calculated as $\% \Delta \mathrm{eCVR} / \% \Delta \mathrm{CPP}$, where $\% \Delta \mathrm{eCVR}$ is the percentage of estimated change in CVR and can be calculated as $\% \Delta \mathrm{CPP}$ $=\mathrm{CBF} \times \% \Delta \mathrm{CVR}$ and $\% \Delta \mathrm{CPP}=\mathrm{MABP}-\mathrm{ICP}^{42}$

If the change in CVR were enough to compensate for the decrease in CPP, the sROR would be 1. Conversely, the absence of vasoconstriction in response to a drop in CPP would yield an sROR of 0 . In other words, when cerebral autoregulation is intact, an equal change in CVR adjusted for a change in CPP leads to an sROR of 1. Conversely, in a pressure-passive circulation (absent autoregulation), no changes in CVR take place and sROR $=0$. Under physiological conditions in humans (intact autoregulation), sROR ranges from 0.85 to $0.95 .{ }^{53}$ In TBI, the static criterion $\mathrm{SROR}>0.5-0.85$ represents a largely intact autoregulation. ${ }^{3,34,42}$

\section{Dynamic Autoregulation}

One important variable that influences the autoregulatory response is time, and this dynamic autoregulation is probably more clinically important than static measures. The first means of assessing dynamic autoregulation was the thigh cuff deflation method, in which a decrease in MABP was the stimulus to study the temporal evolution of the CBF response. ${ }^{1}$ This method is used to describe transient changes in $\mathrm{CBF}$ after rapid changes in MABP. According to this procedure, there is a starting delay of 2 seconds, taking up to 10-15 seconds for the baroreflex mechanism to restore pressure to its previous level. In the normal brain, $\mathrm{CBF}$ volume returns to its baseline level much sooner than does MABP, and the speed of recovery is affected by $\mathrm{PaCO}_{2}$ levels. With the dynamic method, it is also possible to characterize the interaction between pressure autoregulation and other variables such as $\mathrm{PCO}_{2}$ and pharmacological agents (Fig. 4).

The index adopted to measure dynamic autoregulation is the equivalent of that for sROR and is defined as $(\Delta \mathrm{CVR} / \Delta \mathrm{T}) / \Delta \mathrm{MABP}$, where $\mathrm{T}$ is time.

The thigh cuff inflation/deflation approach presents problems in the traumatically brain-injured patient, the most prominent of which is that it requires the manipulation of MABP at a time when the injured brain may least be able to tolerate it. Thus, investigators have sought alternative dynamic measures of autoregulation, often leveraging data already collected through multimodal neuromonitoring.

The Mx is one such measure of dynamic autoregulation. It is a Pearson correlation coefficient between CPP and flow velocity and can indicate autoregulation if the magnitude of slow CPP fluctuations is reasonably large enough to activate an autoregulatory response $(>5 \mathrm{~mm}$ $\mathrm{Hg}$ ). Positive values of the Mx indicate that a change in blood flow velocity is accompanied by a parallel change in CPP-for example, when autoregulation is impaired. Zero or negative values indicate intact autoregulation. This index is valid and correlates significantly with the leg cuff test, $\mathrm{PaCO}_{2}$ reactivity. ${ }^{14}$ The $\mathrm{Mx}$ is calculated from ICP, MABP, and TCD ultrasonography data obtained from the patient in real time.

The PRx is defined as the correlation coefficient between slow waves in ICP and arterial blood pressure. It describes cerebral vasoreactivity and the level of disturbance in physiological vascular responses to changes in MABP. The PRx correlates well with cerebral autoregulation assessed with PET-demonstrated CBF and TCD ultrasonography. ${ }^{12,51}$ In normal conditions, when the vascular bed is reactive, a decrease in MABP produces autoregulatory vasodilation and subsequent increases in CBV and ICP, the latter subject to the pressure-volume characteristic. Therefore, for a reactive vascular bed, the PRx is negative. For a nonreactive vascular bed, the PRx is positive, indicating passive transmission between slow waves of MABP and ICP. The mortality rate is higher in patients with severe TBI and a positive PRx (no reactivity) than in those in whom reactivity is preserved..$^{13}$ Changes in the PRx over time indicate changes in pressure reactivity and may guide the treatment of patients. Steiner and colleagues ${ }^{52}$ are currently developing a commercial system for the online measurement of the PRx in patients. This group has published several reports validating the PRx and its relationship to the pathophysiology of neurological insults, including outcome, in the intensive care unit. A detailed description of the system for calculating the PRx based on multimodal neuromonitoring can be found at http://www.neurosurg.cam.ac.uk/icmplus.

\section{Diagnosis of Abnormal Cerebral Autoregulation and its Role in TBI Management}

Two modalities are currently used in clinical practice to assess cerebral autoregulation: continuous TCD ultrasonography monitoring and PRx monitoring. With continuous TCD ultrasonography monitoring, autoregulation can be monitored online, and any detrimental changes in its state can be interpreted as a warning sign. The ability to monitor serially and grade the autoregulatory response over time is unique to dynamic autoregulatory studies. Transcranial Doppler ultrasonography monitoring is convenient for testing autoregulation in critically ill patients because it requires minimal perturbation in MABP and because it can be easily performed in the intensive care unit. ${ }^{21}$ The dynamic ARI has been shown to correlate closely with the sROR, which has been considered an accurate reflection of cerebral autoregulation.

In clinical practice, it is not always clear what therapeutic actions best mitigate secondary injury. Certainly, an individual patient's optimal CPP is an important parameter. The PRx provides a means of identifying the appropriate CPP treatment strategy for a given patient. Pressure reactivity can be quantified as the slope of the regression line relating MABP and ICP. As mentioned above, Steiner and colleagues ${ }^{52}$ are developing a commercial device for invasive PRx monitoring.

Patients with intact cerebral autoregulation, with a PRx slope $<0.13$, respond best to hypertensive CPPoriented therapy. Patients with impaired autoregulation, with a PRx slope $>0.13$, may have a better outcome with 


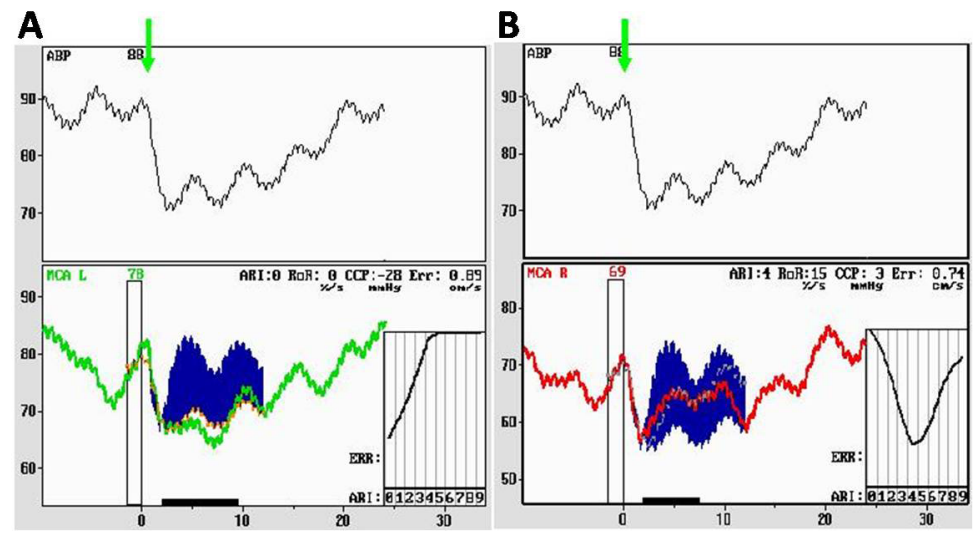

FIG. 4. Graphs showing results of dynamic testing of autoregulation. Observe the adequate decrease in ABP (green arrows) after cuff deflation from 88 to $72 \mathrm{~mm} \mathrm{Hg}$; a decrease of $15 \mathrm{~mm} \mathrm{Hg}$ is considered an adequate stimulus. The MCA velocities decrease after cuff deflation; the decrease lasts $\sim 10$ seconds and then recovers to baseline in the first 25 seconds. Note also that the decrease in velocity occurs immediately after cuff deflation. Values of ARI $(0 \% / \mathrm{second}$ for the left side and $4 \% /$ second for the right side) and values of ROR ( $0 \% /$ second for the left side and $15 \% /$ second for the right side) correspond to absent or severely impaired cerebral autoregulation.

hypotensive ICP-oriented therapy, such as the Lund protocol. ${ }^{22}$ As mentioned above, this observation has been incorporated into the most recent guidelines for the management of severe TBI.,8

The normal $100 \mathrm{~mm} \mathrm{Hg-wide} \mathrm{sROR} \mathrm{range} \mathrm{(50-150}$ $\mathrm{mm} \mathrm{Hg}$ ) can be reduced to a $10 \mathrm{~mm} \mathrm{Hg}$-wide autoregulation range in severe TBI. For each individual patient, this autoregulatory range can also change during the intensive care unit stay. Cerebral perfusion pressure and ICP management should therefore be individually tailored, and optimal CPP and cerebral autoregulation should be reassessed throughout the treatment course.

\section{How to Restore Impaired Cerebral Autoregulation in a Patient With TBI}

\section{Hyperventilation}

In a patient with TBI, hyperventilation improves autoregulation, but this improvement is not homogeneous or long lasting or well documented. The exact time and duration of the therapy required to achieve optimal improvement in cerebral autoregulation requires further characterization. Decreasing the $\mathrm{PCO}_{2}$ values from a baseline of 37 to $28 \mathrm{~mm} \mathrm{Hg}$ results in an improvement in the dynamic ARI. ${ }^{38}$

The mechanism of improvement in autoregulation induced by hyperventilation is not clear. Possible mechanisms to account for this improvement may include an improved CPP, alterations in the $\mathrm{pH}$ value of the CSF, and increased vascular tone. ${ }^{37}$ If hyperventilation significantly reduced the ICP, then an increase in the CPP might contribute to an improvement in autoregulation. Another possible mechanism for improved autoregulation is the effect of hyperventilation on metabolic mediators. ${ }^{15}$ The shift in the acid-base balance in CSF induced by hyperventilation theoretically could affect the efficiency of the autoregulatory response. Increased arterial vascular tone might also improve the efficiency of the autoregulatory response by changing the set point of the regulating vessels to a more favorable position that would allow a rapid change in vascular resistance.

Autoregulation was found to be preserved at a moderately reduced $\mathrm{PCO}_{2}(34 \mathrm{~mm} \mathrm{Hg})$ but was impaired when $\mathrm{PCO}_{2}$ was reduced to low levels $(23 \mathrm{~mm} \mathrm{Hg})$ by more intense hyperventilation. ${ }^{38}$ If an improvement in autoregulation is the result of enhanced vascular tone induced by hypocapnia, then this improvement can be lost if the vascular tone returns to baseline. Moreover, a recent prospective randomized trial of chronic hyperventilation for 5 days in severely head-injured patients did not show a benefit from this treatment. The use of hyperventilation to recover autoregulation reserve has been criticized because it can contribute to cerebral ischemia, as indicated by a lower CBF and higher $\mathrm{O}_{2}$ extraction. Hyperventilation is probably only transiently effective.

\section{Hyperoxia}

A decrease in CBF after the induction of hyperoxia ranges from 13 to $32 \%$, and some authors have assumed that the decrease in blood flow during hyperoxia is induced by a decrease in $\mathrm{ETCO}_{2}$. Floyd et al. ${ }^{16}$ have shown that the decrease in $\mathrm{CBF}$ while breathing $100 \% \mathrm{O}_{2}$ is attributable to the combination of arterial hyperoxia and hypocapnia and that hyperoxia causes a cerebral vasoconstriction independent of the vasoconstriction associated with arterial hypocapnia. The decrease in ICP and flow velocity is probably due to the vasoconstricting effects of hyperoxia, and a small decrease in $\mathrm{ETCO}_{2}$ is caused by breathing $100 \% \mathrm{O}_{2}$. Hyperoxia is followed by an increase in jugular venous $\mathrm{O}_{2}$ saturation and a decrease in $\mathrm{AVDO}_{2}$, suggesting that the ratio between $\mathrm{O}_{2}$ demand and supply is shifted to either a lower cerebral metabolic rate of $\mathrm{O}_{2}$ consumption or an improved delivery. ${ }^{6}$

The increase in brain tissue $\mathrm{O}_{2}$ tension after hyperoxia varies between patients and over time for each patient. The increase in brain tissue $\mathrm{O}_{2}$ tension with hyperoxia appears to be much greater in pathological than in normal 


\section{Rangel-Castilla et al.}

brain tissue. ${ }^{30,35,46}$ Other studies have suggested that $\mathrm{CBF}$ at the site of the $\mathrm{PO}_{2}$ probe might explain these observations. ${ }^{20}$ There are significant changes in ARI in response to hyperoxia throughout the first few days after injury. ${ }^{46}$ Hyperoxia can restore cerebral autoregulation, but overall its effect is limited.

\section{Nitric Oxide, L-Arginine, and Other NOS Drugs}

Nitric oxide has multiple and complex roles in the pathophysiology of TBI. It is a cell membrane-permeable free radical synthesized from the amino acid L-arginine by the enzyme NOS. ${ }^{18}$ Nitric oxide plays a role in numerous general physiological processes of the brain, including the maintenance of basal vasomotor tone, selective neuroprotection, synaptogenesis, and synaptic plasticity. The role of NO in cerebral autoregulation is very controversial. Under pathological conditions, both excesses and deficiencies of NO may have deleterious effects. The depletion of NO produced by endothelial NOS could result in inadequate cerebral perfusion, whereas excesses in NO produced by neuronal NOS and iNOS could lead to neurotoxicity and cellular injury. Such changes in NO metabolism have been implicated in the pathophysiological changes occurring after TBI.

A triphasic (high-low-high) change in the concentration of NO in the brain has been observed after TBI. An immediate increase in NO concentration has occurred within minutes after TBI in experimental models. This phase has been followed by an early decrease (0.5-6 hours) in NO concentrations, which may in part account for the low $\mathrm{CBF}$ observed during this period after injury. The decrease in NO can result from either a decrease in NO production or rapid inactivation of NO. The late phase ( $>6$ hours) is an increase in NO associated with a return to normal or even elevated levels of $\mathrm{CBF}$. Elevated expression of iNOS protein in cerebrovascular smooth muscles has been observed during this phase, ${ }^{11}$ and CSF levels of NO have been reported to peak between 20 and 42 hours after TBI.

During the early phase, a period of relative deficiency in $\mathrm{NO}$ and a low level of $\mathrm{CBF}$, the administration of Larginine has been shown to improve $\mathrm{CBF}$ and neurological outcome in models of TBI. ${ }^{10,28}$ During the late peak in NO after TBI due to the activity of iNOS, the inhibition of iNOS has been neuroprotective in experimental models of TBI. ${ }^{23,31,32}$

\section{Erythropoietin}

Erythropoietin has been shown to be a neuroprotector and reduce neuronal death in many in vivo and in vitro models. The overall expression of erythropoietin receptors by neurons, astrocytes, and capillary endothelial cells elicited by hypoxia and ischemia ${ }^{45}$ supports a hypothetically well-organized network in the setting of neuronal injury. Experimental studies have shown that erythropoietin can induce a significant reduction in inflammation and neuronal apoptosis; ${ }^{50}$ decrease necrosis, brain edema, ${ }^{54}$ and capillary breakdown; and restore cerebral autoregulation. The use of erythropoietin in TBI may hold promise for future clinical applications.

\section{Conclusions}

In the absence of a gold-standard method of assessing cerebral autoregulation, additional studies are necessary to establish the accuracy of different measures of cerebral autoregulation in patients with TBI.

Cerebral autoregulation is seen as a protective mechanism; however, its exact role in secondary injury after TBI is not known. Cerebral autoregulation is altered after injury, but more information is needed regarding its role as a causative agent and a factor in guiding therapy as well as the determinants of outcome in TBI. Nevertheless, cerebral autoregulation is one of the multiple factors involved in the pathophysiology of TBI. Further investigations are required to analyze and measure a multivariate dynamic method of describing interrelationships with other factors involved in cerebral vasculature.

A desirable pharmacological therapy would induce a lasting reduction in CBV with a minimal effect on CBF. This drug would have its principle vasoconstriction within the venous compartment, where $70 \%$ of the blood volume is located.

The inclusion of cerebral autoregulation in multimodal neuromonitoring of the traumatically brain-injured patient is approaching "prime time," and an appreciation of the interplay between the cerebral autoregulation status and critical care management may aid in the individualization of treatment for severe TBI.

\section{Disclaimer}

The authors report no conflict of interest concerning the materials or methods used in this study or the findings specified in this paper.

\section{Acknowledgment}

The authors are grateful to Brodus Franklin, B.S., for assistance in the preparation of Figs. 1 and 2.

\section{References}

1. Aaslid R, Lindegaard KF, Sorteberg W, Nornes H: Cerebral autoregulation dynamics in humans. Stroke 20:45-52, 1989

2. Astrup J, Siesjo BK, Symon L: Thresholds in cerebral ischemia-the ischemic penumbra. Stroke 12:723-725, 1981

3. Bouma GJ, Muizelaar JP: Cerebral blood flow, cerebral blood volume, and cerebrovascular reactivity after severe head injury. J Neurotrauma 9 (1 Suppl):S333-S348, 1992

4. Bouma GJ, Muizelaar JP, Bandoh K, Marmarou A: Blood pressure and intracranial pressure-volume dynamics in severe head injury: relationship with cerebral blood flow. J Neurosurg 77:15-19, 1992

5. Bouma GJ, Muizelaar JP, Stringer WA, Choi SC, Fatouros P, Young HF: Ultra-early evaluation of regional cerebral blood flow in severely head-injured patients using xenon-enhanced computerized tomography. J Neurosurg 77:360-368, 1992

6. Bratton SL, Chestnut RM, Ghajar J, McConnell Hammond FF, Harris OA, Hartl R, et al: Guidelines for the management of severe traumatic brain injury. II. Hyperosmolar therapy. J Neurotrauma 24 (1 Suppl):S14-S20, 2007

7. Bratton SL, Chestnut RM, Ghajar J, McConnell Hammond FF, Harris OA, Hartl R, et al: Guidelines for the management of severe traumatic brain injury. IX. Cerebral perfusion thresholds. J Neurotrauma 24 (1 Suppl):S59-S64, 2007

8. Bratton SL, Chestnut RM, Ghajar J, McConnell Hammond 
FF, Harris OA, Hartl R, et al: Guidelines for the management of severe traumatic brain injury. VIII. Intracranial pressure thresholds. J Neurotrauma 24 (1 Suppl):S55-S58, 2007

9. Carney NA, Ghajar J: Guidelines for the management of severe traumatic brain injury. Introduction. J Neurotrauma 24 (1 Suppl):S1-S2, 2007

10. Cherian L, Chacko G, Goodman JC, Robertson CS: Cerebral hemodynamic effects of phenylephrine and L-arginine after cortical impact injury. Crit Care Med 27:2512-2517, 1999

11. Clark RS, Kochanek PM, Schwarz MA, Schiding JK, Turner DS, Chen M, et al: Inducible nitric oxide synthase expression in cerebrovascular smooth muscle and neutrophils after traumatic brain injury in immature rats. Pediatr Res 39:784-790, 1996

12. Czosnyka M, Guazzo E, Whitehouse M, Smielewski P, Czosnyka Z, Kirkpatrick P, et al: Significance of intracranial pressure waveform analysis after head injury. Acta Neurochir (Wien) 138:531-532, 1996

13. Czosnyka M, Smielewski P, Lavinio A, Czosnyka Z, Pickard JD: A synopsis of brain pressures: which? when? are they all useful? Neurol Res 29:672-679, 2007

14. Czosnyka M, Smielewski P, Piechnik S, Steiner LA, Pickard JD: Cerebral autoregulation following head injury. J Neurosurg 95:756-763, 2001

15. Dewey RC, Pieper HP, Hunt WE: Experimental cerebral hemodynamics. Vasomotor tone, critical closing pressure, and vascular bed resistance. J Neurosurg 41:597-606, 1974

16. Floyd TF, Clark JM, Gelfand R, Detre JA, Ratcliffe S, Guvakov D, et al: Independent cerebral vasoconstrictive effects of hyperoxia and accompanying arterial hypocapnia at 1 ATA. J Appl Physiol 95:2453-2461, 2003

17. Gross PM, Heistad DD, Strait MR, Marcus ML, Brody MJ: Cerebral vascular responses to physiological stimulation of sympathetic pathways in cats. Circ Res 44:288-294, 1979

18. Gross SS, Wolin MS: Nitric oxide: pathophysiological mechanisms. Annu Rev Physiol 57:737-769, 1995

19. Heistad DD: Protection of cerebral vessels by sympathetic nerves. Physiologist 23:44-49, 1980

20. Hlatky R, Valadka AB, Gopinath SP, Robertson CS: Brain tissue oxygen tension response to induced hyperoxia reduced in hypoperfused brain. J Neurosurg 108:53-58, 2008

21. Hlatky R, Valadka AB, Robertson CS: Intracranial pressure response to induced hypertension: role of dynamic pressure autoregulation. Neurosurgery 57:917-923, 2005

22. Howells T, Elf K, Jones PA, Ronne-Engstrom E, Piper I, Nilsson $\mathrm{P}$, et al: Pressure reactivity as a guide in the treatment of cerebral perfusion pressure in patients with brain trauma. $\mathbf{J}$ Neurosurg 102:311-317, 2005

23. Jafarian-Tehrani M, Louin G, Royo NC, Besson VC, Bohme GA, Plotkine M, et al: $1400 \mathrm{~W}$, a potent selective inducible NOS inhibitor, improves histopathological outcome following traumatic brain injury in rats. Nitric Oxide 12:61-69, 2005

24. Junger EC, Newell DW, Grant GA, Avellino AM, Ghatan S, Douville CM, et al: Cerebral autoregulation following minor head injury. J Neurosurg 86:425-432, 1997

25. Kajita Y, Takayasu M, Dietrich HH, Dacey RG Jr: Possible role of nitric oxide in autoregulatory response in rat intracerebral arterioles. Neurosurgery 42:834-841, 1998

26. Kirkness CJ, Mitchell PH, Burr RL, Newell DW: Cerebral autoregulation and outcome in acute brain injury. Biol Res Nurs 2:175-185, 2001

27. Lassen NA: Cerebral blood flow and oxygen consumption in man. Physiol Rev 39:183-238, 1959

28. Lee J, Ryu H, Ferrante RJ, Morris SM Jr, Ratan RR: Translational control of inducible nitric oxide synthase expression by arginine can explain the arginine paradox. Proc Natl Acad Sci U S A 100:4843-4848, 2003

29. Lewelt W, Jenkins LW, Miller JD: Autoregulation of cerebral blood flow after experimental fluid percussion injury of the brain. J Neurosurg 53:500-511, 1980

30. Longhi L, Valeriani V, Rossi S, De Marchi M, Egidi M, Stocchetti N: Effects of hyperoxia on brain tissue oxygen tension in cerebral focal lesions. Acta Neurochir Suppl 81:315-317, 2002

31. Louin G, Marchand-Verrecchia C, Palmier B, Plotkine M, Jafarian-Tehrani M: Selective inhibition of inducible nitric oxide synthase reduces neurological deficit but not cerebral edema following traumatic brain injury. Neuropharmacology 50:182-190, 2006

32. Lu J, Moochhala S, Shirhan M, Ng KC, Teo AL, Tan MH, et al: Neuroprotection by aminoguanidine after lateral fluid-percussive brain injury in rats: a combined magnetic resonance imaging, histopathologic and functional study. Neuropharmacology 44:253-263, 2003

33. Marion DW, Darby J, Yonas H: Acute regional cerebral blood flow changes caused by severe head injuries. J Neurosurg 74:407-414, 1991

34. Matta BF, Stow PJ: Sepsis-induced vasoparalysis does not involve the cerebral vasculature: indirect evidence from autoregulation and carbon dioxide reactivity studies. Br J Anaesth 76:790-794, 1996

35. Meixensberger J, Dings J, Kuhnigk H, Roosen K: Studies of tissue PO2 in normal and pathological human brain cortex. Acta Neurochir Suppl (Wien) 59:58-63, 1993

36. Melamed E, Lavy S, Bentin S, Cooper G, Rinot Y: Reduction in regional cerebral blood flow during normal aging in man. Stroke 11:31-35, 1980

37. Muizelaar JP, Marmarou A, Ward JD, Kontos HA, Choi SC, Becker DP, et al: Adverse effects of prolonged hyperventilation in patients with severe head injury: a randomized clinical trial. J Neurosurg 75:731-739, 1991

38. Newell DW, Weber JP, Watson R, Aaslid R, Winn HR: Effect of transient moderate hyperventilation on dynamic cerebral autoregulation after severe head injury. Neurosurgery 39:35-43, 1996

39. Osol G, Halpern W: Myogenic properties of cerebral blood vessels from normotensive and hypertensive rats. Am J Physiol 249:H914-H921, 1985

40. Panerai RB: Assessment of cerebral pressure autoregulation in humans-a review of measurement methods. Physiol Meas 19:305-338, 1998

41. Pannier JL, Weyne J, Leusen I: Effects of changes in acid-base composition in the cerebral ventricles on local and general cerebral blood flow. Eur Neurol 6:123-126, 1971

42. Puppo C, Lopez L, Caragna E, Biestro A: One-minute dynamic cerebral autoregulation in severe head injury patients and its comparison with static autoregulation. A transcranial Doppler study. Neurocrit Care 8:344-352, 2008

43. Robertson CS, Narayan RK, Gokaslan ZL, Pahwa R, Grossman RG, Caram P Jr, et al: Cerebral arteriovenous oxygen difference as an estimate of cerebral blood flow in comatose patients. J Neurosurg 70:222-230, 1989

44. Sahuquillo J, Poca MA, Arribas M, Garnacho A, Rubio E: Interhemispheric supratentorial intracranial pressure gradients in head-injured patients: are they clinically important? J Neurosurg 90:16-26, 1999

45. Sakanaka M, Wen TC, Matsuda S, Masuda S, Morishita E, Nagao M, et al: In vivo evidence that erythropoietin protects neurons from ischemic damage. Proc Natl Acad Sci U S A 95:4635-4640, 1998

46. Sarrafzadeh AS, Kiening KL, Bardt TF, Schneider GH, Unterberg AW, Lanksch WR: Cerebral oxygenation in contusioned vs. nonlesioned brain tissue: monitoring of $\mathrm{PtiO} 2$ with Licox and Paratrend. Acta Neurochir Suppl 71:186-189, 1998

47. Schmidt EA, Czosnyka M, Steiner LA, Balestreri M, Smielewski P, Piechnik SK, et al: Asymmetry of pressure 


\section{Rangel-Castilla et al.}

autoregulation after traumatic brain injury. J Neurosurg 99:991-998, 2003

48. Schmidt EA, Piechnik SK, Smielewski P, Raabe A, Matta BF, Czosnyka M: Symmetry of cerebral hemodynamic indices derived from bilateral transcranial Doppler. J Neuroimaging 13:248-254, 2003

49. Simard JM, Bellefleur M: Systemic arterial hypertension in head trauma. Am J Cardiol 63:32C-35C, 1989

50. Siren AL, Fratelli M, Brines M, Goemans C, Casagrande S, Lewczuk P, et al: Erythropoietin prevents neuronal apoptosis after cerebral ischemia and metabolic stress. Proc Natl Acad Sci U S A 98:4044-4049, 2001

51. Steiner LA, Coles JP, Czosnyka M, Minhas PS, Fryer TD, Aigbirhio FI, et al: Cerebrovascular pressure reactivity is related to global cerebral oxygen metabolism after head injury. J Neurol Neurosurg Psychiatry 74:765-770, 2003

52. Steiner LA, Czosnyka M, Piechnik SK, Smielewski P, Chatfield D, Menon DK, et al: Continuous monitoring of cerebrovascular pressure reactivity allows determination of optimal cerebral perfusion pressure in patients with traumatic brain injury. Crit Care Med 30:733-738, 2002

53. Tiecks FP, Lam AM, Aaslid R, Newell DW: Comparison of static and dynamic cerebral autoregulation measurements. Stroke 26:1014-1019, 1995

54. Verdonck O, Lahrech H, Francony G, Carle O, Farion R, Van de Looij Y, et al: Erythropoietin protects from post-traumatic edema in the rat brain. J Cereb Blood Flow Metab 27:13691376, 2007

Manuscript submitted June 16, 2008.

Accepted August 25, 2008.

Address correspondence to: Leonardo Rangel-Castilla, M.D., Division of Neurosurgery, University of Texas Medical Branch, 301 University Boulevard, John Seally Annex, Suite 9.121 ZC, Galveston, Texas 77555. email: lerangel@utmb.edu. 